\title{
Contribuições do programa institucional de bolsas de iniciação à docência (PIBID) para a inserção profissional de professoras iniciantes
}

\author{
Contributions of the institutional programme of teaching initiation (PIBID) for the \\ professional insertion of beginning teachers
}

\author{
Glaucia Signorelli ${ }^{1}$ \\ Marli André ${ }^{2}$
}

\begin{abstract}
Resumo
O foco deste estudo é o processo de inserção profissional de professoras iniciantes, egressas do Programa Institucional de Bolsas de Iniciação à Docência (Pibid). O objetivo principal é analisar os efeitos da participação no Pibid, na prática profissional dessas professoras. As participantes da pesquisa são 12 professoras iniciantes, ex-pibidianas, egressas do curso de Pedagogia da Universidade Federal de Uberlândia, campus do Pontal - Ituiutaba/MG, que estavam atuando na educação infantil e nos anos iniciais do ensino fundamental, em escolas públicas estaduais e municipais, e sete supervisoras dessas escolas. Foram realizados dois grupos de discussão com as ex-pibidianas e entrevistas individuais com as supervisoras. As professoras iniciantes relataram desafios enfrentados por terem sido direcionadas às turmas mais difíceis da escola, pela falta de material e de acolhimento dos gestores e das colegas de trabalho. No entanto, descreveram situações que mostravam iniciativa e segurança para enfrentar os desafios encontrados, os quais as inspiravam a buscar novas estratégias de ensino, atividades diferenciadas e a criar vínculos afetivos com os alunos, no desejo de promover a aprendizagem. As supervisoras comprovaram as iniciativas das ex-pibidianas, valorizando-as por terem domínio do conteúdo a ser trabalhado em sala de aula, pela capacidade de análise das situações difíceis e pelas soluções criativas no enfrentamento dos problemas encontrados.
\end{abstract}

Palavras-chave: Professora iniciante; Pibid; Inserção profissional.

\begin{abstract}
This article focuses on the process of professional insertion of beginning teachers, graduates from the Institutional Program of Teaching Initiation Scholarships (Pibid). The aim of the study was to analyze the effects of participation in Pibid, in the professional practice of beginning teachers. The research participants are 12 beginning teachers, ex PIBID members, graduates of the Pedagogy course at the Federal University of Uberlândia, Pontal Campus -

\footnotetext{
1 Doutora em Educação - Psicologia da Educação Universidade Federal de Uberlândia E-mail: glauciasignorelli@gmail.com

${ }^{2}$ Doutorado em Psicologia da Educação pela University of Illinois at Urbana Champaign, Estados Unidos(1978). Docente e vice coordenador de Programa de Pós-graduação da Pontifícia Universidade Católica de São Paulo PUC -SP. E-mail: marliandre@ pucsp.br
} 
Ituiutaba/MG, who were working in early childhood education and elementary School, in state and municipal public schools, and seven supervisors of these schools. Two discussion groups were conducted with the ex-pibidianas and individual interviews with the supervisors. The new teachers reported challenges faced by being directed to the most difficult classes in the school, the lack of school supplies and lack of support from managers and their work mates. However, they described situations that showed initiative and security to face the challenges, which inspired them to seek new teaching strategies, differentiated activities and to create affective links with the students, in the desire to promote learning. The supervisors reinforced the initiatives of the beginners, valuing them for mastering the subjects to be taught in the classroom, for the ability to analyze difficult situations and for creative solutions in facing the problems encountered.

Keywords: Beginning teachers; Pibid; Professional insertion.

\section{Introdução}

Dentre as políticas públicas de formação de professores implementadas no Brasil, nos últimos anos, o Programa Institucional de Bolsas de Iniciação à Docência - Pibid, criado em 2007, no âmbito da CAPES (Coordenação de Aperfeiçoamento de Pessoal do Ensino Superior) revelou resultados positivos ao promover o contato direto dos estudantes de licenciatura, com o cotidiano da escola pública.

O Pibid foi instituído com o propósito de promover a entrada dos licenciandos na escola, a fim de que possam apropriar-se dos elementos inerentes ao trabalho docente, tanto os que ocorrem na sala de aula como outros que se dão nos diversos espaços escolares. $\mathrm{O}$ programa justifica-se pela necessidade de fortalecer a articulação entre a formação acadêmica e a profissional, contribuindo para o aprimoramento dos cursos de licenciatura e para a melhoria do ensino na educação básica, conforme está explicitado em documento oficial da CAPES (BRASIL, 2013).

Ao ingressarem no Pibid, os estudantes têm oportunidade de vivenciar o contexto escolar em suas várias dimensões, observar e participar de atividades dentro e fora da sala de aula, de tal forma que possam fazer um juízo do que significa ser professor e o que irão encontrar em sua prática profissional.

Nesse sentido, o Pibid tem conquistado um grande espaço no cenário educacional conforme os dados de uma avaliação externa, abrangente, em que o programa "foi considerado como uma das melhores iniciativas em política coadjuvante à formação inicial de 
professores para a educação básica (GATTI et al., 2014, p. 111). Segundo essa mesma avaliação, as discussões em torno do Pibid que ocorreram em todo o país, reforçaram as contribuições do programa e seus efeitos positivos "junto à comunidade acadêmica e as implicações diretas da parceria universidade e escolas sobre a formação do futuro professor." (GATTI et al., 2014, p. 15).

A contribuição do programa para a formação inicial, assim como para a melhoria dos cursos de licenciatura e para as escolas parceiras, têm sido destacadas em muitas pesquisas (entre as quais: ANDRÉ, 2016; ALVES, 2017, PANAGIO, SAMENTO e ROCHA, 2018). No entanto, após doze anos de implementação do programa, é preciso ir além desses resultados que se referem ao processo formativo, para verificar seu impacto ou seus efeitos na prática profissional dos egressos. Afinal, uma medida clara da contribuição do programa é a marca deixada na atuação profissional daqueles que passaram pela experiência.

Ao ingressarem na docência, os recém formados entram em uma fase bastante específica, permeada por mudanças que afetam tanto o campo profissional como a vida pessoal, já que estão se inserindo no mundo do trabalho. Alves (1998) afirma que a inserção profissional não diz respeito apenas à passagem do contexto escolar para o profissional, mas é muito mais profunda, na medida em que transforma identidades e altera as categorias de identificação social - estudante/profissional, jovem/adulto - aspecto que chega a causar o "choque de realidade".

Huberman (1992) é um dos autores que mencionou o choque de realidade, quando estudou o ciclo de vida profissional dos docentes. Segundo ele, os 2-3 primeiros anos da carreira é um período que além de ser de muitas aprendizagens, é, sobretudo, de definições de posturas e comportamentos que serão adotados no exercício profissional. É um período repleto de desafios.

Ainda, na perspectiva do autor, quando iniciam, os professores necessitam apreender a dimensão prática do ofício de ensinar e reportar-se aos saberes aprendidos na formação inicial, ao mesmo tempo em que têm que resolver as ocorrências do dia a dia da sala de aula. A situação é marcada por uma intensidade de sentimentos que vão do prazer de ter a sua própria sala de aula ao desespero de ter que lidar com algo novo para o qual não se sentem preparados. E, embora este início seja mais complexo para alguns do que para outros, em geral "há regressões, becos sem saída, momentos de arranque, descontinuidades". (HUBERMAN, 1992, p. 38). 
É comum conforme os estudos de Vaillant e Marcelo Garcia (2012), que os professores iniciantes passem por situações conflitantes, pois não estão plenamente preparados para o exercício profissional. No entanto, à medida que colocam em prática os saberes adquiridos na formação inicial, vão experimentando e refinando modos de ser professor. Isso pode levar alguns anos e, conforme a realidade enfrentada, há professores que desistem da profissão e esta é, segundo Vaillant e Marcelo Garcia (2012) a fase em que esse fato é mais frequente.

Nesse sentido, considerando que a maioria dos professores iniciantes é acometida por dificuldades no início da carreira, por não conhecerem muito bem a dinâmica da escola e da sala de aula (SIGNORELLI, 2016); mas, considerando que o Pibid promove o contato direto do licenciando com a realidade escolar, sendo acompanhado pelos professores da escola e da universidade, pareceu oportuno investigar como os egressos do Pibid vivenciam sua inserção na docência. Algumas questões deram origem à pesquisa: os egressos do Pibid tiveram dificuldades similares às dos iniciantes que não passaram por programa de iniciação à docência? Ou tiveram uma inserção profissional diferente?

A par desses questionamentos, o objetivo da pesquisa desenvolvida foi analisar os efeitos da participação no Pibid, na prática profissional de professoras iniciantes.

Nesta pesquisa, optou-se pela abordagem metodológica de cunho qualitativo, que se fundamenta na perspectiva que valoriza o papel ativo do sujeito no processo de produção do conhecimento e que concebe a realidade como uma construção social (ANDRÉ, 2005, p. 47). Assim, buscou-se conhecer as práticas culturais, as linguagens e as formas de interações dos sujeitos/participantes, como, também, os significados por eles atribuídos às suas experiências cotidianas, suas opiniões, saberes, representações.

Como se pretendeu investigar as experiências vividas pelos egressos do Pibid no momento de sua inserção profissional, buscou-se ouvir esses sujeitos. Assim, os participantes desta pesquisa são 12 professoras iniciantes, ex-pibidianas, egressas do curso de Pedagogia da Universidade Federal de Uberlândia, campus do Pontal - Ituiutaba/MG, que estavam atuando na educação infantil e nos anos iniciais do ensino fundamental, em escolas públicas estaduais e municipais e sete supervisoras das escolas em que atuavam. As professoras tinham entre seis meses e dois anos de experiência na docência, o que as situa na condição de professoras iniciantes, de acordo com Huberman (1992). 


\section{Universidade e escola: espaços de formação dos professores}

A formação inicial de professores tem sido objeto de debate nos mais diversos âmbitos pela complexidade com que se apresenta e pelos problemas indicados, principalmente quanto aos cursos que preparam os futuros professores, entre os quais se destacam: currículos de formação mais teóricos que práticos, pouca atenção a questões da prática escolar, falta de articulação entre as disciplinas de formação específica e as de formação pedagógica, estágios abreviados e pouco explorados, o distanciamento entre as instituições de formação e a escola campo, entre outros.

Destaca-se, entre esses vários problemas, o distanciamento entre a universidade e a escola provocado pelas diferentes visões entre o discurso acadêmico e a prática pedagógica e a da falta de conexão entre os saberes profissionais necessários à docência, resultando, segundo Tardif (2002, p. 45), "na dissociação entre o conhecer e o fazer na educação.”.

Tais considerações indicam a necessidade de articulação entre a formação inicial e a prática escolar de modo que se estabeleça um diálogo profícuo entre essas duas instituições, aproximando os estudos teóricos e as situações concretas de trabalho dos professores nas escolas. Nesse sentido, o Programa Institucional de Bolsa de Iniciação à Docência - Pibid, apresenta-se como uma alternativa para enfrentar esse distanciamento na busca de ultrapassar a histórica separação entre teoria e prática, entre o campo acadêmico e o profissional.

Várias pesquisas confirmam as contribuições do Pibid na formação dos professores, como por exemplo, a de Ambrosetti et al. (2015) que reforça os benefícios da aproximação entre universidade e escola e a promoção de condições favoráveis à iniciação dos futuros professores no ambiente escolar; a pesquisa de André (2016) que revela aspectos muito valorizados pelos licenciandos por possibilitar o contato com a realidade das escolas, fazer conexões entre teoria e prática e trabalhar coletivamente. O já citado estudo avaliativo do Pibid, realizado por Gatti et al. (2014) também atesta o valor que o Programa vem agregando à formação docente, com base em um grande número de depoimentos de seus participantes de todos os estados do país.

Revista Devir Educação, Lavras, vol.3, n.2, p.27-52 jul./dez., 2019. 


\section{OO DEVIR EDUCAÇÃO}

ISSN: 2526-849X

A implementação dessa política pública de formação de professores traz uma nova perspectiva ao enfrentamento dos problemas que envolvem tanto a formação como o início da carreira, citados por vários autores, como: formação desvinculada da prática, pelo distanciamento entre universidade e escolas (ZEICHNER, 2010); déficit de qualidade dos conhecimentos disciplinares dos cursos e sua insuficiente articulação com o conhecimento pedagógico e a prática docente (VAILLANT, 2006); condições inadequadas do trabalho do professor, baixa remuneração, poucos incentivos na carreira, formação continuada desvinculada da realidade dos professores e alunos (GATTI; BARRETO; ANDRÉ, 2011); início da vida profissional permeado pelo isolamento e pouco apoio aos professores, configurando uma fase de grande evasão na carreira (MARCELO GARCIA, 2010).

Os autores também fazem propostas para superar os problemas, entre eles Zeichner (2010), que defende a articulação entre as dimensões teórica e prática na organização curricular da formação inicial e, insiste que os futuros professores devem aprender a profissão na escola. O autor sugere ainda que na formação inicial haja o "cruzamento de fronteiras" entre as instituições formadoras - universidades e escolas-, de modo que ações conjuntas sejam desenvolvidas, tomando a realidade escolar como pano de fundo, o que poderá ajudar os futuros professores a buscarem o entrelaçamento entre o conhecimento acadêmico e a prática profissional.

Outro autor que reitera a importância de aproximar universidade e escola é Nóvoa (2009), quando destaca o papel que devem ter os professores em exercício, na formação dos licenciandos, trazendo-os para o centro da cena escolar e abrindo possibilidades para que a prática profissional se torne conteúdo da formação. Uma forte proposição de Nóvoa é que a formação de professores seja construída dentro da profissão, o que atribui, necessariamente, um papel formativo às escolas básicas, lócus de atuação dos professores.

Marcelo Garcia (2010) é outro autor que propõe que a formação dos professores tome o contexto e as experiências produzidas no interior das escolas, de forma organizada, intencional e contínua. $\mathrm{O}$ autor critica o modelo de formação descontextualizado, que não consegue provocar mudanças por não fazer as articulações necessárias entre o que se aprende na academia e o que se vivencia no exercício da prática docente.

Nessa lógica, é possível que se estabeleça uma relação dialógica e compartilhada entre a universidade e a escola enquanto espaços de formação. E, mesmo que ambas as instituições tenham funções específicas, ou seja, a universidade responsável pela preparação dos futuros 
professores, assegurando-lhes a construção de uma base teórica e metodológica, para enfrentamento dos problemas educacionais; e a escola como local de trabalho e de formação continuada dos professores, são duas instituições cujas funções se associam no percurso da formação docente, pois guardam estreita relação com a ação pedagógica dos professores.

As proposições apresentadas pelos autores supracitados, requerem uma revisão dos cursos e instituições formadoras. A distância que historicamente separou escolas e universidades não é mais concebível. Um diálogo permanente entre as instituições formadoras e as escolas básicas e o estabelecimento de uma relação colaborativa entre elas, podem ser altamente promissores à formação.

\section{O início da docência: dificuldades, desafios e descobertas}

Ser professor é uma tarefa bastante complexa, principalmente nos dias atuais, pois junto à função de ensinar, os docentes têm que assumir outras atividades inerentes à docência: planejar, avaliar, organizar a classe, preparar material didático, escolher estratégias de ensino, conhecer o conteúdo, conhecer os alunos e motivá-los, participar de reuniões, cuidar da disciplina da classe, atender aos pais, colaborar em atividades que envolvem toda a escola, seguir regras, cumprir horários extras, gerir problemas individuais dos alunos, educar, formar, ensinar valores e outras atividades.

Ser professor iniciante é mais complexo ainda, tendo em vista que o professor tem que realizar todas essas atividades, desde o primeiro dia, assumindo total responsabilidade pela condução da classe e, muitas vezes sem ter a quem recorrer nas suas dúvidas. Assim, diante desta circunstância diversa e nada promissora, certamente os iniciantes se interrogam: $\mathrm{O}$ que fazer agora? Qual o melhor caminho para conduzir a classe? E se eu não conseguir um bom resultado na aprendizagem dos meus alunos?

É comum que o início da carreira seja envolvido por dúvidas, sentimentos de medo e insegurança e que os professores iniciantes coloquem em questão seus saberes, suas concepções e crenças, entrecortados por manifestações de frustração e desencorajamento. Em Cavaco (1995) encontra-se uma explicação que sustenta o dilema que recai sobre os professores iniciantes: 
O início da actividade profissional é, para todos os indivíduos, um período contraditório. Se, por um lado, o ter encontrado um lugar, um espaço na vida activa, corresponde à confirmação da idade adulta, ao reconhecimento do valor da participação pessoal no universo do trabalho, à perspectiva da construção da autonomia, por outro, as estruturas ocupacionais raramente correspondem à identidade vocacional definida nos bancos da escola [...]. Assim, é no jogo de procura de conciliação, entre aspirações e projetos e as estruturas profissionais, que o jovem professor tem de procurar o seu próprio equilíbrio dinâmico, reajustar, mantendo o sonho que dá sentido aos seus esforços. (CAVACO, 1995, p. 162-163).

Concorda-se com Cavaco que o início da docência é um jogo e que os professores iniciantes têm que se equilibrar entre tantas exigências, para não sucumbir às dificuldades. Assim, não é possível olhar para essa condição dos professores iniciantes e deixar que resolvam sozinhos as dificuldades ou que se percam no emaranhado de "nós" que a docência lhes coloca. Por isso, há que se preocupar com os professores iniciantes que chegam às escolas e, são muitos os fatores que nos levam a isso.

Dentre esses fatores, estão os de ordem prática que são aqueles que se referem ao exercício profissional e, geralmente, são os que mais incomodam os professores iniciantes. Mizukami (2002), Nóvoa (2009), Marcelo Garcia (2010) defendem que a prática é um componente da profissão que vai se constituindo no exercício profissional à medida que os professores vão aprendendo e construindo os saberes da docência, o que demanda aprendizagens que extrapolam o espaço da sala de aula.

Outros autores como Alves (2017), Ambrosetti et al. (2015) entre outros, concordam que os primeiros anos da docência são intensos aos iniciantes, pois esses têm muito que aprender e a maneira como essas aprendizagens ocorrem, determinam, muitas vezes, sua permanência ou não na profissão e seu perfil profissional. Se permanecerem, desordens de ordem pessoal e profissional podem ocorrer e, entre dificuldades e desafios a vencer, com seu repertório de saberes em conflito (experiência da escolarização, saberes da formação, saberes da prática em processo de construção), com a necessidade de desenvolver-se profissionalmente, os professores têm que superar esses obstáculos, muitas vezes sozinhos. Entretanto, defendem os autores, se encontrarem apoio, se forem acompanhados pedagogicamente, conseguem maior equilíbrio emocional, pessoal e profissional. 


\section{QO DEVIR EDUCAÇÃO \\ ISSN: 2526-849X}

Para os professores que resistem às intempéries do início da carreira, não há somente dissabores na fase inicial, pois o estudo Gabardo e Hobold (2014), revelou que os iniciantes vivenciam também descobertas e aprendizagens que vão lhes ajudando a compor seu repertório profissional. Vão, aos poucos se adaptando, cada um a seu tempo e à sua maneira, às condições de trabalho, aos alunos e às situações do dia a dia que envolvem o fazer docente. Nesse processo vão colocando em prática suas crenças, valores e concepções, mesmo que por meio de "tentativas e erros, e geração de expectativas e sentimentos fortes e por vezes contraditórios (GABARDO; HOBOLD, 2014, p. 3).

Superar as dificuldades do início da carreira não é fácil, pois muitos professores não têm o apoio dos profissionais mais experientes da escola, chegando até a abandonar a carreira por não terem conseguido conduzir os conflitos comuns que ocorrem nas escolas. Além disso muitas vezes são desafiados pelos colegas mais experientes, o que põe em cheque a autoestima e agrava o sentimento de solidão e isolamento.

Percebe-se que são vários os domínios a serem alcançados para que o início da carreira dos professores seja menos vulnerável, e para que os iniciantes possam se manter no controle de sua atuação e do seu desenvolvimento profissional.

\section{O Contexto da Pesquisa: o Pibid Pedagogia da Universidade Federal de Uberlândia - Campus do Pontal $^{3}$}

As participantes dessa pesquisa foram bolsistas do Pibid, subprojeto Pedagogia, desenvolvido em classes de Educação Infantil e Ensino Fundamental/Alfabetização em escolas estaduais e municipais. A carga horária cumprida pelas licenciandas era de 20 horas semanais conforme projeto institucional da Universidade Federal de Uberlândia - UFU, sendo, 8 horas na escola, 6 horas de atividades na universidade - reuniões, planejamento e estudos, e $6 \mathrm{~h}$ de atividades individuais para preenchimento de fichas, escrita do diário de campo e estudos.

\footnotetext{
${ }^{3}$ Subprojeto disponível no site institucional do Pibid - Universidade Federal de Uberlândia. Disponível em: <http://www.pibid.prograd.ufu.br/?q=SubPedagogiaPontal>. Acesso em: 21 de set. de 2019
} 
Dentre as ações desenvolvidas pela professora coordenadora do subprojeto, professora supervisores e licenciandos, destaca-se: a observação pedagógica nas salas de aula sob a orientação de uma professora da escola parceira e da supervisora do Pibid; o planejamento de atividades individuais das escolas respeitando-se suas particularidades; o planejamento coletivo de atividades como parte comum do desenvolvimento dos subprojeto em todas as escolas, como a construção de material didático, oficina de jogos e brincadeiras e outras; as reuniões com os grupos de trabalho de cada escola, dirigidas pelos coordenadores e supervisores das escolas participantes, a fim de acompanhar as atividades desenvolvidas, promover troca de experiências e avaliação do Pibid; os grupos de estudos que visam o aprofundamento teórico de conteúdos da formação das licenciandas e supervisoras; as visitas técnicas; a participação em eventos e publicação de artigos, relatórios, relatos de experiências. As ações propostas neste subprojeto nos remetem a uma concepção de formação de professores que ressalta a aprendizagem da docência pelo contato direto e intenso das licenciandas com a escola básica, durante seu processo formativo, mediado pelas experiências acadêmico-científicas no âmbito das universidades. Igualmente importante é o papel da professora coordenadora, chamada a interagir ativamente com as escolas, conhecendo-as por dentro; das professores nas escolas e supervisoras do programa, atuando co-formadoras de suas futuras colegas; e das licenciandas cuja imersão no contexto escolar possibilita entrar em contato com a realidade e se envolver com diferentes dimensões do trabalho docente.

\section{Procedimentos de Coleta de Dados}

Como fonte principal na coleta de dados, optou-se pela realização de grupos de discussão, que de acordo com Weller (2006), documentam experiências coletivas e características sociais de um grupo.

Foram convidados a participar dos grupos todos os egressos do Pibid/Pedagogia da universidade citada. Todos os que confirmaram o aceite do convite, compareceram na data e horário previstos para o encontro.

Foram realizados dois grupos de discussão, que tiveram duração aproximada de 90 minutos, cada um composto por seis ex-pibidianas. As discussões foram orientadas por um 
roteiro, que incluía questões como: O Pibid as preparou para o início da docência? (questão de aquecimento) Que elementos foram facilitadores e dificultadores na sua inserção profissional? Que desafios enfrentaram no início da docência e como os enfrentaram? (questões de desenvolvimento) Pretendem continuar na docência? (questão de finalização). As duas sessões ocorreram em um ambiente especialmente organizado para as discussões, num clima descontraído e amigável.

Além dos grupos de discussão, foram realizadas entrevistas com sete supervisoras das escolas onde as iniciantes estavam atuando, com o objetivo de captar suas percepções sobre o desempenho das professoras iniciantes.

A interpretação dos dados baseou-se no método denominado por André (1983, p. 67) como Análise de Prosa, "[...] considerada uma forma de investigação do significado dos dados qualitativos". A autora propõe esse método de análise de dados como uma alternativa que amplia a forma de conceber o objeto de estudo e assim orienta: "Em lugar de um sistema pré-especificado de categorias, eu sugiro que tópicos e temas vão sendo gerados a partir do exame dos dados e de sua contextualização no estudo" (ANDRÉ, 1983, p. 67).

Os encontros dos grupos e as entrevistas foram gravados, posteriormente transcritos pela pesquisadora, e constituíram o corpus de análise. Após várias leituras e organização do material, foram identificados os tópicos (os assuntos, os conteúdos) e os temas (agrupamento dos assuntos/ conteúdos comuns), os quais possibilitaram a definição das seguintes categorias temáticas: as primeiras experiências na carreira docente; a chegada na escola e o acolhimento às iniciantes; as contribuições do Pibid ao início da carreira; o que dizem as iniciantes sobre o Pibid; o Pibid e os motivadores para o início da carreira; a prática pedagógica das iniciantes sob o olhar das supervisoras das escolas.

\section{As primeiras experiências na carreira docente}

Em geral, quando chegam às escolas, os professores iniciantes trazem os conhecimentos formulados durante sua trajetória estudantil, seja na educação básica ou na formação superior, mas ainda têm muito que aprender na nova posição - a de professor em uma sala de aula ensinando seus alunos. Assim, enquanto ensinam, os professores iniciantes vão aprendendo a conduzir a sala de aula, a lidar com os conteúdos, com o comportamento 
dos alunos, a se relacionar com os pais e com seus pares e tantas outras aprendizagens necessárias à docência.

A depender de como encaram essa fase ou o modo como são recebidos no contexto escolar, a entrada na carreira pode ser fácil ou difícil, amena ou inquietante, alegre ou triste ou, muitas vezes, uma mistura desses sentimentos. Alguns professores conseguem passar por essa fase de forma mais tranquila, inclusive fazendo importantes descobertas, mas a maioria sofre as agruras do início da carreira.

Não foi diferente com as professoras iniciantes que participaram desta pesquisa. Seus relatos mostraram que a inserção profissional tem apresentado uma diversidade de sentimentos que vão do medo e insegurança, causados pelas dificuldades enfrentadas, às alegrias e à sensação de bem estar e dever cumprido por estarem superando desafios e realizando descobertas pessoais e profissionais.

Destacam-se a seguir, alguns aspectos relacionados às primeiras experiências das professoras iniciantes nas escolas.

\section{A chegada na escola $\mathbf{e} o$ acolhimento às iniciantes}

Dos sentimentos e dificuldades das iniciantes ao chegarem à escola, alguns são unânimes e vividos com maior ou menor intensidade, mas todos representam a experiência que tocou cada professora nesse período de inserção profissional. A intensidade com que vivem esse processo e os dispositivos do contexto em que estão inseridas é que diferencia as experiências vividas por uma e outra professora. Os depoimentos das professoras iniciantes revelam como foram os seus primeiros dias na escola:

No primeiro dia de aula, olhando para as crianças eu pensei: meu Deus e agora? O que eu tenho que fazer? Como agir com crianças de quatro anos e meio. Isso mexeu comigo e eu fiquei meio apavorada [...]. (TAMARA).

No começo eu fiquei super ansiosa, mãos geladas, voz trêmula. Estava feliz por estar ali, mas sentia um peso enorme sobre minhas costas, acho que era de pensar que eu era a responsável por aquela turma, eu tinha que ensinar e 
eles tinham que aprender, então eu acho que isso é o que pesa no começo mesmo [...]. (PATRÍCIA).

Considera-se natural que esses sentimentos se manifestem, pois as professoras estão ingressando na vida profissional em que surgem fatos, situações, episódios, os mais variados, que exigem tomada de decisões em meio a dúvidas, a resultados imprevistos, ações urgentes que podem funcionar ou não. Para essas iniciantes, que em geral não dispõem de apoio institucional de colegas ou da gestão a quem pedir ajuda, resta o bom senso, a vontade de acertar e a lembrança das experiências como alunas, às quais fatalmente recorrem em seus primeiros passos na docência. Esta constatação reforça a importância de que a escola promova experiências enriquecedoras para seus alunos, pois elas podem deixar marcas positivas que afetarão outros alunos.

As professoras iniciantes contaram como foi seu primeiro dia como docentes:

Fui para a designação, na própria escola e quando fui chamada me perguntaram se eu queria $3^{\circ}$ ou $4^{\circ}$ ano, eu escolhi o $3^{\circ}$ e a pessoa me disse que eu poderia ir para a sala de aula, que os alunos estavam lá a minha espera, fiquei super nervosa, não sabia o que fazer, mas fui. (NAIARA).

Comecei no berçário e nos primeiros dias, meu Deus!!! O que eu estou fazendo aqui? [...] se eu tivesse a oportunidade de escolher eu não escolheria berçário, mas peguei e só depois eu descobri porque sobrou apenas o berçário, é que ninguém quis, nenhuma das professoras que estavam na creche queriam berçário, que além de ser difícil tem muitos rótulos, professora do berçário é rotulada de babá, de que não tem conhecimento [...]. (NATÁLIA).

São relatos distintos, permeados pelos sentimentos de surpresa diante do inesperado e da falta de preparo da escola para acolher devidamente essas profissionais. São situações do contexto escolar que evidenciam as dificuldades vividas logo na chegada à escola, fato comprovado por Giovanni e Guarnieri (2014) ao assinalarem que a chegada de docentes iniciantes ao ambiente de trabalho é marcada por fragilidades, dificuldades e situações de vulnerabilidade, como ocorreu com essas professoras.

Além dessas, outras dificuldades foram relatadas como, por exemplo, a falta de apoio da equipe gestora: "A escola não me proporciona esse encontro com as colegas, e quando 
estamos iniciando precisamos desse apoio, desse suporte" (AMANDA). Também falam da solidão: “[...]eu senti um impacto mesmo, pois me senti sozinha, só eu e meus alunos e são neles que eu me apego para desenvolver meu trabalho" (NARA). Mais dramáticos ainda são os depoimentos que revelam sentimentos de rejeição, frieza, distanciamento: "Eu, pra falar a verdade, me senti um zero à esquerda [risos] um nada né, tamanha a desconsideração com a minha presença" (FABIANA); "ninguém olha pra gente não, acho que se fosse de cabelo azul, nem assim me enxergariam ali como professora. [...] É uma sensação ruim [...]”. (CLARA).

Mesmo sendo esse o cenário que as professoras encontraram no início da carreira, suas reações surpreenderam, pois não se submeteram às condições definidas pela escola. Outros sentidos, relacionados à descoberta e ao enfrentamento dos desafios, se sobrepuseram às dificuldades encontradas, muitos deles atribuídos às contribuições da participação no Pibid, aspectos que serão destacados a seguir.

\section{As contribuições do Pibid ao início da carreira}

As contribuições do Pibid como programa de iniciação à docência foi um ganho irrevogável à formação das professoras iniciantes. Com uma matriz epistemológica que toma como pressuposto o diálogo, a reflexão, o trabalho coletivo, a indissociabilidade dos conhecimentos teóricos e práticos, a problematização da prática, entre outros, o Pibid mobilizou professores universitários, professores das escolas básicas, licenciandos e as instituições das quais fazem parte esses sujeitos, para implementar uma formação que privilegia a escola como espaço de aprendizagem da docência.

\section{O que dizem as iniciantes sobre o Pibid}

O protagonismo das professores iniciantes durante a participação no Pibid possibilitou-lhes uma aproximação maior com a docência, com a sala de aula e com os 
alunos. Pondera-se que essa participação no programa foi um elemento a mais na formação profissional dessas professoras iniciantes, considerando que nem todos os licenciandos do curso participam do programa.

Nos grupos de discussão com as professoras iniciantes, uma das questões formuladas foi se o Pibid as havia preparado para a docência. As professoras dos dois grupos foram unânimes na afirmação de que as experiências do Pibid foram fundamentais para o trabalho que hoje realizam na escola. Os depoimentos que seguem são reveladores disso:

Bom, eu penso que o Pibid foi como um suporte para chegarmos à escola [...], pois, quando eu assumi minha sala eu já tinha certo domínio da sala de aula, já tinha uma noção de como lidar com as crianças, sabia o que fazer em determinadas situações, o planejamento era algo que eu sabia fazer, porque essa foi uma prática muito presente no Pibid que ajudou demais. (TAMARA).

Eu concordo plenamente, o Pibid foi realmente um apoio, tudo de bom aconteceu para contribuir com nossa formação, para nos aproximar da sala de aula, da escola, compreender a realidade, saber como as coisas acontecem lá, foi muito bom mesmo. (NAIARA).

As falas das professoras são incisivas quanto à importância do Pibid na fase de preparação para a docência. Sendo essa uma das intenções do programa, ou seja, possibilitar aos licenciandos o contato direto com a realidade da escola e as dimensões do trabalho docente, parece que, nesse contexto, essa intenção foi, de fato, alcançada. Essa iniciação no campo profissional destaca a importância de práticas formativas que integrem os conhecimentos da universidade e a prática nas escolas, aspecto sustentado por Nóvoa (2009) ao defender uma formação que abra possibilidades aos licenciandos para vivenciar experiências reais.

Outras professoras também afirmam: "Eu quero falar sim sobre a riqueza das práticas que vivenciamos no Pibid. [...] tudo conversado, tudo partilhado, analisado coletivamente, esse é um grande ganho em nossa formação, é algo realmente motivador (AMANDA); [...] o Pibid me deu mais força, me proporcionou conhecer mais a escola, me fez aproximar da sala de aula (NARA); tenho plena segurança pra dizer que o Pibid foi muito importante para mim como professora (CIDA). 
A par disso, nos dedicamos a olhar para os aspectos que foram motivadores no Pibid e que tiveram grande significado para o desenvolvimento da prática profissional no início da carreira.

\section{O Pibid e os motivadores para o início da carreira}

As iniciantes destacaram uma multiplicidade de elementos vivenciados no Pibid que auxiliaram o início da carreira, entre eles a importância da orientação e acompanhamento recebidos durante a participação no programa:

O Pibid é muito rico, desenvolvemos muitas atividades de intervenção, oficinas, grupo de estudo, diário de campo, escrita de artigos científicos, apresentação de trabalhos em eventos. Muito bom tudo isso. Mas isso se deve em grande parte ao trabalho de nossa coordenadora que foi muito envolvida, dedicada e estava sempre junto conosco, tanto na escola como na universidade. (IZADORA).

Era muito bom poder contar com a ajuda da nossa supervisora, ela estava sempre presente e sempre disposta a nos orientar, em sala de aula quando fazíamos alguma atividade com as crianças ela dava a opinião sobre o plano e nos ajudava na condução da aula também. (NARA).

Nota-se nestes depoimentos, menção a uma combinação de estratégias de orientação e acompanhamento - intervenção, oficinas, grupos de estudo, escrita de artigos e do diário de campo, acompanhamento das atividades na escola - valorosos na formação dessas professoras, a ponto de serem agora realçados. No entanto, o destaque é a orientação precisa da coordenadora do subprojeto e da supervisora, o que convalida a importância do acompanhamento das estudantes em formação. No Pibid, subprojeto Pedagogia, essa foi a estratégia de aproximação entre universidade e escola e entre licenciandas e o campo profissional, pois é uma forma de aproximá-las da docência e de empreender análises conjuntas dos desafios do trabalho docente e de alternativas para sua superação.

Gomes e Felício (2015), ao tratarem das contribuições do Pibid à formação inicial, defendem a iniciação antecipada como propõe o Pibid e ponderam que os licenciandos ao 
compartilharem da experiência dos professores nas escolas, geram um benefício ao seu próprio processo de aprendizagem, uma vez que o aprender vincula-se, também, às trocas de informações e conhecimentos que podem ocorrer entre formadores, professores da educação básica e licenciandos. Evidencia-se, assim, um aprendizado derivado do compartilhamento de experiências.

Outro destaque das professoras, diretamente relacionada ao acompanhamento, foi o aprendizado do planejamento das atividades, considerado um ganho importante no processo formativo para a prática profissional. No relato, isso fica evidente:

Havia no Pibid todo um processo de preparação, de planejamento e o planejar prepara a gente, porque uma aula sem planejamento é muito falha, se eu chegar na sala de aula sem um planejamento acho que ficaria muito perdida, se eu não escrever a aula eu não consigo desenvolvê-la [...]. Lembro que no Pibid a gente assentava com a coordenadora, planejava, discutia e isso era muito bom, dava segurança na hora de desenvolver a atividade e isso eu carreguei para minha prática. (AMANDA).

Aqui se evidencia algo que vai além do fato de aprender a planejar que, por si só, é um ganho enorme para a formação, pois se sabe o valor de uma aula bem planejada. Percebe-se, nesse caso, que o planejamento como atividade didática, não é apenas mais uma atividade docente, mas uma prática formativa que, segundo Gatti (2009, p. 92), proporciona "a aquisição de conhecimentos, valores, atitudes de diferentes naturezas [...]”. Para as professoras iniciantes, o planejamento é uma ação cujo sentido é delineador de um trabalho pedagógico efetivo e crítico, pois se pauta no ir e vir, planejar e replanejar, efetivar o movimento de ação-reflexão-ação, sendo, conforme exprime Gatti (2009), um dos fundamentos para discutir a qualidade formativa dos professores, muito promissor à prática docente.

Em consequência do ato de aprender a planejar, as professoras ressaltam outro aprendizado: considerar as necessidades individuais de seus alunos e alunas:

Esse foi mesmo um grande aprendizado proporcionado pelo Pibid, quando estou fazendo meu plano penso nas crianças, nas necessidades de cada uma, de cada uma mesmo, ainda mais eu que trabalho no projeto tempo integral

Revista Devir Educação, Lavras, vol.3, n.2, p.27-52 jul./dez., 2019. 
[Proeti] na sala de apoio, eu tenho alunos do $1^{\circ}, 2^{\circ}$ e $3^{\circ}$ ano, cada um é diferente então é fundamental eu atender cada um na sua necessidade. (NARA).

Concordo com a Nara, quando planejo peno no meu aluno, no que ele sabe, no que não sabe, senão pode acontecer do meu planejamento não ser eficaz. (CLARA).

Esses depoimentos ratificam a prática das professoras, permeada por características docentes que, segundo Hubermam (1992, p. 36), estão impregnadas de "domínios de competência pedagógica". Também Marcelo Garcia (2010, p. 112) explica que este é um conhecimento situacional, ligado a ação e que se desenvolve contextualmente, caracterizando "uma forma de competência profissional (expertise)", aspectos proporcionados na iniciação à docência pelo Pibid e colocados em prática no exercício da profissão.

Segurança foi outro elemento que a participação no Pibid lhes propiciou. Um elemento subjetivo, mas construído a partir de situações objetivas vivenciadas no programa. Em seus relatos, as professoras iniciantes foram mostrando as situações que favoreceram esse sentimento de segurança: a ajuda mútua, o planejamento conjunto, as orientações pontuais da coordenadora, o tempo para estudo e preparação de material, a oportunidade de rever o planejamento, o fato de não ir para a sala de aula com dúvidas, a presença e o acompanhamento da supervisora. Nota-se também que são ações e atividades de diferentes naturezas, as quais reforçam os objetivos do Pibid e que, neste caso, foram significativas à formação e ao início da carreira, como expõe uma professora:

[...] ser pibidiana, ter o apoio das colegas e a orientação da professora coordenadora e ainda da professora regente da sala que sempre dava aquela ajudinha básica na hora de controlar as crianças foi fundamental, deu aquela segurança, eu agora sei onde estou pisando. (NATÁLIA).

Está evidente que as ações vivenciadas no Pibid trouxeram segurança às professoras, sendo benéficas tanto à formação quanto ao exercício atual da docência. Segurança é, segundo Marcelo Garcia (2010), uma "necessidade emocional" dos professores e, para obtê-la, eles precisam de apoio e de orientação, fato marcante no contexto deste grupo de professoras. 
Vivenciar a relação teoria e prática foi outro ganho proporcionado pelo Pibid. Distantes da prática, ainda nos primeiros anos da formação inicial, revelaram a tensão existente entre esses dois elementos (GAMBOA, 2010), mas que foi diminuindo à medida que as professoras foram compreendendo a relação dialética entre ambas, proporcionada pelas ações do Pibid. Nos extratos abaixo duas iniciantes contam um pouco sobre isso:

Eu vivo todos os dias a relação teoria e prática [...]. Na formação isso é meio distante para nós, [mas] depois do Pibid isso ficou bem claro [...]. Além disso é essa relação que vai nos ajudar a desenvolver boas aulas ter boas ideias, a trabalhar de um jeito diferente pra mudar a prática, pra inovar. (FABIANA).

Eu também consigo enxergar essa relação teoria e prática e acho que é muito importante para o professor, porque, eu sei que a gente não pode ficar só na prática ou só na teoria, essas duas coisas funcionam juntas e foi no Pibid que eu percebi isso. (NARA).

Os depoimentos expressam uma visão articulada entre a teoria e prática e as professoras iniciantes confirmam que a formação lhes proporcionou isso, mesmo que essa seja, ainda hoje, uma questão nodal no interior dos cursos de licenciatura pelo tratamento muitas vezes dicotômico. Nota-se que a preparação obtida na formação inicial, passando pelo Pibid, responde às suas necessidades, pela forma como sistematizam os saberes docentes.

Os dados aqui apresentados permitem afirmar que as atividades no interior de um curso de formação de professores necessitam, de fato, passar pelo campo de atuação profissional, nesse caso, a escola, e implementar ações que problematizem a realidade, que estabeleçam o diálogo entre sujeitos, para que os futuros professores possam construir os conhecimentos profissionais necessários à docência. Nos depoimentos das professoras, observa-se que as ações implementadas foram significativas e indicaram que é possível essas duas instituições atuarem simultaneamente, dando uma nova configuração aos espaços formativos.

O Pibid tem cumprido esse papel de aproximar as licenciandas do campo de atuação profissional, de modo que percebam sua complexidade e compreendam a lógica teóricoprática da formação, para transformá-la em caminhos que as ajudem a "munir-se de um 
conjunto de elementos que podem responder, criativamente, aos problemas enfrentados no cotidiano escolar" (FRANCO, 2008, p. 111).

O discurso favorável ao Pibid, apresentado pelas professoras iniciantes, não é representativo apenas deste grupo, mas de inúmeros licenciandos por todo o Brasil, além de seus coordenadores e supervisores, aspecto comprovado no estudo avaliativo realizado por Gatti et al. (2014, p. 111).

\title{
A prática pedagógica das iniciantes sob o olhar das supervisoras das escolas
}

Os depoimentos das supervisoras (orientadoras pedagógicas) das escolas onde atuam as iniciantes foi uma importante referência para atestar as implicações do Pibid nas práticas das iniciantes. Foi fundamental ouvi-las. Eis um dos relatos:

\begin{abstract}
Eu acompanho de perto dentro da minha função e posso dizer da professora Nara que estava comigo ano passado e da Tamara que ainda acompanho, que as aulas delas são muito prazerosas para as crianças, diversificadas, nada repetitivo, estressante. As atividades são lúdicas e as meninas estão preocupadas mesmo com a construção do conhecimento pela criança, então, partem disso, que a criança é capaz de construir conhecimentos, essa é uma fala muito presente nelas e vejo que não é da boca pra fora, pois sabem como fazer para que isso aconteça. Já falei da rodinha, momento que exploram muito a linguagem oral, cantam, conversam, as crianças falam, contam casos. Tem muita contação de histórias e é sempre de forma diversificada [...]. (ALESSANDRA).
\end{abstract}

A supervisora que já acompanhava as professoras quando eram pibidianas, fala agora sobre o desempenho da iniciante na sala de aula, evidenciando o domínio de saberes e fazeres essenciais às situações que vivenciam com seus alunos, destaca o uso de práticas pedagógicas diversificadas, uma concepção construtivista de conhecimento, e enfatiza o protagonismo das crianças.

Outra supervisora revela a disposição da ex-pibidiana que atua em sua escola, para criar, para fazer trabalho de campo, para buscar os recursos necessários e fazer seus alunos aprenderem:

Revista Devir Educação, Lavras, vol.3, n.2, p.27-52 jul./dez., 2019. 
Ela não fica parada, está conosco há quase um ano e todos os dias ela tem uma coisa diferente que quer fazer e quando não tem os recursos que ela quer, ela inventa, é uma brincadeira, é uma batalha com os alunos, é um passeio pelo bairro. Outro dia eu tive que deixar aqui as minhas atividades e ir com ela dar uma volta pelo bairro, [...]. Achei legal acompanhar a turma. Antes de sair ela conversou com as crianças e disse que deveriam observar tudo no bairro, as ruas, as casas, se tinha comércio, sinalização de trânsito, então antes, ela preparou os alunos para o passeio. [...] na conclusão da atividade os alunos fizeram uma exposição de desenhos com as devidas explicações daquilo que aprenderam e eles realmente aprenderam muito com esse passeio. (HELLEN).

Nesta situação descrita pela supervisora, nota-se como a professora se posiciona frente ao ensino e comprova o domínio dos conhecimentos tanto pedagógicos como do conteúdo ensinado, explicitado na sua forma de agir, além de boas ideias que parecem fazer parte de um planejamento bem estruturado. Ao implementar sua ação, a professora o faz de forma criativa e provoca a curiosidade da criança, estimulando a construção do conhecimento.

Assim, pelas observações das supervisoras é possível apreender como as iniciantes estão atuando, o que fazem e como lidam com situações inesperadas da prática. Em seus depoimentos esses aspectos são destacados:

[...] elas têm muito conhecimento e se preparam muito bem para a aula e com isso não têm nenhum tipo de insegurança em passar o conteúdo. [...] sabem como lidar com a criança, têm carinho por elas, sabem lidar com as dificuldades das crianças, têm boas estratégias para a sala de aula [...] sabe argumentar. (VIVIAN).

Vejo que ela tem vontade e coragem para enfrentar os problemas, não fica parada esperando a criança sair de uma situação sozinha e sabemos que isso não vai acontecer se o professor não estiver atento aos alunos, principalmente os que têm dificuldades, eles, sozinhos, não avançam, não aprendem. (ELIANA).

Os depoimentos revelam que há um equilíbrio entre o que sabem e fazem as professoras e que, embora iniciantes, conseguem resolver situações complexas da prática. As ações dessas docentes são típicas de quem já sabe onde buscar ajuda e o que pode fazer para 


\section{OO DEVIR EDUCAÇÃO}

ISSN: 2526-849X

intervir. Assim, uma possível explicação para esse tipo de atuação de professoras iniciantes, com tão pouca experiência, deve-se à participação no Pibid, que desenvolveu uma postura investigativa da prática, em que tiveram oportunidade de observar a ação dos professores, analisar concepções, planejar e desenvolver atividades, fato que lhes possibilitou a apropriação de referências importantes para lidar com os problemas diários da sala de aula.

Dessa relação entre teoria e ação ou saber e fazer, é que se adquire o que Malglaive (1997, p. 57) denomina como inteligência "prevenida", ou seja, uma inteligência construída a partir de um saber na ação, mobilizado, em simultâneo, com os saberes teóricos, que juntos ajudam a compreender a própria experiência. Advém de uma experiência pessoal, que se constrói eficaz, se articulada a um fundamento teórico coerente à ação. Por uma metáfora, o autor ilustra: não se aprende a podar roseiras apenas comprando um livro que ensine a técnica, "para se saber podar roseiras, tem de se podar roseiras". (MALGLAIVE, 1997, p. 56). No mesmo sentido, pode-se afirmar que não se ensina crianças apenas a partir dos preceitos teóricos encontrados nos livros, para saber ensinar crianças, tem-se que ensinar crianças. É o que as professoras iniciantes estão fazendo, pois nota-se que mostram essa inteligência "prevenida" aliando saber e fazer.

Por isso, fica evidente que participar das situações reais que acontecem nas escolas, é uma forma de compreender as exigências da profissão, que envolvem não somente as necessidades dos alunos em processo de aprendizagem, mas as do próprio professor.

\section{Algumas considerações}

A proposta do Pibid, de aproximação entre universidade e escola, orientada por uma concepção de formação de professores que prevê o contato direto e intenso dos licenciandos com a escola básica, mediado pelas experiências acadêmico-científicas no âmbito das universidades revelou-se exitosa no contexto da presente pesquisa.

Os dados indicaram aprendizagens significativas das licenciandas, que no início da docência, mesmo enfrentando situações difíceis, sentiram-se fortalecidas e seguras para buscar recursos materiais e humanos que as ajudassem a desempenhar sua função docente. As gestoras das escolas em que as iniciantes atuavam foram incisivas no reconhecimento da 


\section{OO DEVIR EDUCAÇÃO}

ISSN: 2526-849X

competência dessas professoras, quanto ao domínio dos saberes e fazeres da sala de aula, quanto ao planejamento das atividades, quanto ao uso de estratégias criativas com as crianças e quanto a iniciativa para resolver situações complexas.

Ficou evidente, na análise dos dados, o importante papel dos professores formadores, chamados a interagir ativamente com as escolas, conhecendo-as por dentro e promovendo situações de estímulo à reflexão e à atitude investigativa. Da mesma forma, ficou evidente a ação relevante dos professores nas escolas, que na supervisão dos pibidianos puderam repensar suas práticas e atuarem como co-formadores, desenvolvendo novas habilidades.

Essa aproximação das iniciantes ao campo de atuação profissional ajudou-as a compreender a lógica teórico-prática da formação e a responder, com conhecimento e criatividade, os problemas e necessidades da prática pedagógica que desenvolviam. As professoras iniciantes revelaram um compromisso com uma educação crítica e transformadora para seus alunos e expressaram que no exercício da profissão há sempre muito o que aprender.

Assim, os dados mostraram que o Pibid, como uma política pública de formação de professores, tem produzido resultados efetivos não só à formação, mas, também, à prática de seus egressos.

Obviamente, há, ainda, muitos aspectos a serem considerados e investigados no campo de inserção dos professores na carreira, mas os dados da pesquisa não deixam dúvidas que o campo de formação de professores pode se fortalecer, e muito, com um trabalho sistemático e bem orientado de aproximação entre universidade e escola. Ganham os cursos de licenciatura que se mobilizam para rever suas práticas formativas, ganham os professores supervisores das escolas que recebem jovens motivados e desejosos de aprender e de compartilhar saberes, ganham os alunos das escolas que são expostos a novas estratégias de ensino. Finalmente, ganham os futuros professores, que estarão melhor preparados para o exercício da docência.

\section{Referências}

ALVES, Mariana Gaio. Inserção na vida activa de licenciados: a construção de identidades sociais profissionais. Sociologia - problemas e práticas, Lisboa, v.1, n. 26, p. 131-147, Jul. 1998. 
ALVES, Roberlúcia Rodrigues. Professores Iniciantes Egressos do Pibid em Ação: aproximações à sua prática. 2017. 137 p. Dissertação (Mestrado em Educação) Universidade Estadual do Ceará. Fortaleza, 2017.

AMBROSETTI, Neusa Banhara et al. O Pibid e a aproximação entre universidade e escola: implicações na formação profissional dos professores. Atos de Pesquisa em Educação, Blumenau, v. $10, \quad$ n. 2, p. 369-392, mai./ago. 2015. Disponível em: <http://dx.doi.org/10.7867/1809-0354.2015v10n2p369-392>. Acesso em: 20 jan. 2019.

ANDRÉ, Marli. Texto Contextos e Significados: algumas questões na análise de dados qualitativos. Cadernos de Pesquisa, São Paulo, n.45, p. 66-71, mai. 1983.

ANDRÉ, Marli. Pesquisa em educação: questões de teoria e de método. Educ. Tecnol., Belo Horizonte, v. 10, n. 1, p. 29-35, jan/jun. 2005.

ANDRÉ, Marli. Políticas de iniciação à docência para uma formação profissional qualificada. In André, M. (Org.). Práticas Inovadoras na Formação de Professores. Campinas: Papirus, 2016, p. 49-70.

BRASIL. DEB. Relatório de gestão 2013. Brasília: Fundação CAPES, 2013. Disponível em: <https://www.capes.gov.br/images/stories/.../2562014-relatrorio-DEB-2013-web.pdf>. Acesso em: 12 ago. 2019.

CAVACO, Maria. Helena. Ofício do professor: o tempo e as mudanças. In: NÓVOA, A. Profissão Professor. Porto: Porto Editora, 1995, p. 155-189.

FRANCO, Maria Amélia Santoro. Entre a lógica da formação e a lógica das práticas: a mediação dos saberes pedagógicos. Educação e Pesquisa, São Paulo, v. 34, n. 1, p. 109-126, jan./abr. 2008.

GABARDO, Claudia Valéria L.; HOBOLD, Marcia de Souza. O bem e o mal estar dos professores iniciantes: um estudo com professores do ensino fundamental. In: Congresso Internacional Sobre Professorado Principiante e Inserção Profissional à Docência, 4. 2014, Curitiba. Anais... Curitiba: Editora UTFPR, 2014. 1 CD-ROM.

GAMBOA, Sílvio Sanchez. Teoria e prática: uma relação dinâmica e contraditória. Motrivivência, Florianópolis, n. 8, p. 31-45, jan. 1995. ISSN 2175-8042. Disponível em: <https://periodicos.ufsc.br/index.php/motrivivencia/article/view/22595/20588>. Acesso em: 19 set. 2019. doi:https://doi.org/10.5007/\%x.

GATTI, Bernadete. Formação de Professores: condições e problemas atuais. Revista Brasileira de Formação de Professores, São Paulo, v. 1, n. 1, p. 90-102, mai. 2009.

GATTI, Bernadete. et al. Um estudo avaliativo do Programa Institucional de Bolsa de Iniciação à Docência (PIBID). São Paulo: FCC/SEP, 2014. 
GATTI, Bernadete; BARRETO, Elba Siqueira de Sá; ANDRÉ, Marli. Políticas docentes no Brasil: um estado da arte. Brasília: UNESCO, 2011.

GOMES, Claudia; FELÍ́CIO, Helena Maria dos Santos. Contribuições do Pibid/Unifal-MG na formação de professores: reflexões, compreensões e desafios. In: BORGES, Maria Celia; MARTINS, S. E. C.; ZEULli, Elizandra. (Org.). Políticas e Contribuições das Práticas do Pibid para a formação de professores. Uberlândia: EDUFU, 2015, p. 91-112.

GIOVANNI, Luciana Maria; GUARNIERI, Maria Regina. Pesquisas sobre professores iniciantes e as tendências atuais da reforma da formação de professores: distância, ambiguidades e tensões. In: GIOVANNI, L. M.; MARIN, A. J. (Org.). Professores iniciantes: diferentes necessidades em diferentes contextos. Araraquara: Junqueira e Marin, 2014. p. 5-12.

HUBERMAN, Michael. O Ciclo de vida profissional dos professores. In: NÓVOA, Antônio. (Org.). Vidas de professores. 2. ed. Portugal: Porto Editora, 1992, p. 31-61.

MALGLAIVE, Gerard. Formação e Saberes Profissionais: entre a teoria e a prática. In: CANÁRIO, R. (Org.). Formação e situações de trabalho. Portugal: Porto Editora, 1997, p. 53-63.

MARCELO GARCIA, Carlos. O professor iniciante, a prática pedagógica e o sentido da experiência. Revista Brasileira de Pesquisas sobre Formação de Professores, Belo Horizonte, v. 3, n. 3, ago./dez. 2010.

MIZUKAMI, Maria da Graças Nicoletti et al. Escola e aprendizagem da docência: processos de investigação e formação. São Carlos: EdUFSCAR, 2002.

NÓVOA, Antônio. Para uma formação de professores construída dentro da profissão. In: . Professores: imagens do futuro presente. Lisboa: Educa, 2009. p. 25-46.

PAPI, Silmara de Oliveira Gomes; MARTINS, Pura Lucia Oliveira. As pesquisas sobre professores iniciantes: algumas aproximações. Educação em Revista, Belo Horizonte, v. 26, n. 3, p. 39-56, dez. 2010.

PANIAGO, Rosenilde Nogueira; SARMENTO, Teresa; ROCHA, Simone Albuquerque da. O Pibid e a inserção à docência: experiências possibilidades e dilemas. Educação em Revista, Belo Horizonte, v. 34, n.1. , p. 1-31, mar. 2018.

SIGNORELli, Gláucia. Inserção Profissional de Egressos do Pibid: desafios e aprendizagem da docência. 2016. 243 p. Tese (Doutorado Educação: Psicologia da Educação) - Pontifícia Universidade Católica de São Paulo, São Paulo, 2016.

TARDIF, Maurice. Saberes docentes e formação profissional. 4. ed. Rio de Janeiro: Vozes, 2002.

VAILLANT, Denise; MARCELO GARCIA, Carlos. Ensinando a ensinar: as quatro etapas de uma aprendizagem. Curitiba: Ed. UTFPR, 2012. 
WELLER, Wivian. Grupos de discussão na pesquisa com adolescentes e jovens: aportes teórico-metodológicos e análise de uma experiência com método. Educação e Pesquisa, São Paulo, v. 32, n. 2, p. 241-260, mai/ago, 2006.

ZEICHNER, Kenneth. Repensando as conexões entre a formação na universidade e as experiências de campo na formação de professores em faculdades e universidades. Educação, Santa Maria, v. 35, n. 3, p. 479-504, set/dez, 2010. 